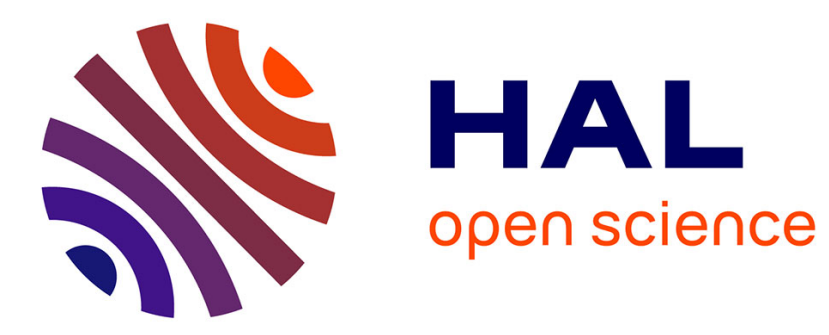

\title{
Nanopatterns Produced by Directed Self-Assembly in Block Copolymer Thin Films
}

\author{
Virginie Ponsinet
}

\section{To cite this version:}

Virginie Ponsinet. Nanopatterns Produced by Directed Self-Assembly in Block Copolymer Thin Films. Polymer Surfaces in Motion. Unconventional Patterning Methods, 4, Springer International Publishing, pp.73-97, 2015, 978-3-319-17430-3. 10.1007/978-3-319-17431-0_4 . hal-01222568

\section{HAL Id: hal-01222568 \\ https://hal.science/hal-01222568}

Submitted on 30 Sep 2017

HAL is a multi-disciplinary open access archive for the deposit and dissemination of scientific research documents, whether they are published or not. The documents may come from teaching and research institutions in France or abroad, or from public or private research centers.
L'archive ouverte pluridisciplinaire HAL, est destinée au dépôt et à la diffusion de documents scientifiques de niveau recherche, publiés ou non, émanant des établissements d'enseignement et de recherche français ou étrangers, des laboratoires publics ou privés. 


\title{
Nanopatterns Produced by Directed Self-Assembly in Block Copolymer Thin Films
}

\author{
Virginie Ponsinet
}

\subsection{Introduction}

For the last 30 years, block copolymers (BCP) have held the promises of new functional nanomaterials due to their fascinating spontaneous spatial organization as well as their complex properties, combining those of the individual blocks. The pathway is long, starting at the first synthesis mastered in the 1950s [1], travelling through full thermodynamics descriptions [2], the discovery of industrially viable synthesis technologies [3], and the first patents in one of the expected most appealing applicative fields [4]. This path still has obstacles and challenges ahead before block copolymer nanostructures really come out of the research laboratories. Until then, and for many more years, BCPs will keep researchers busy and amazed by their capacities to spontaneously produce chemically and topographically patterned surfaces [5]. Block copolymers nanopatterning is only one of the many opportunities offered by macromolecules at interfaces as detailed in the other chapters of this book, as well as previous enlightening literature [6]. But they indisputably present many advantages compared to alternative methods for the production of nanopatterned surfaces, including the tunability of size and morphologies of the domains, the ease of processing on many types of surfaces and the possibility to smarten the systems up with chemical functionalities. Theoretical and experimental tools have been readily derived from that developed for interfacial phenomena in mixed polymer systems [7]. The block copolymer thin film morphologies therefore offer a genuine technological platform for the generation of surface nanopatterns as well as ordered thin films, for a wide range of possible applications (cf. Fig. 4.1) mostly in optics, or based on their templating possibilities [8-10]. Two specific thin

\footnotetext{
V. Ponsinet

Centre de Recherche Paul Pascal, UPR 8641, CNRS - University of Bordeaux,

Pessac 33600, France

e-mail: ponsinet@crpp-bordeaux.cnrs.fr
} 


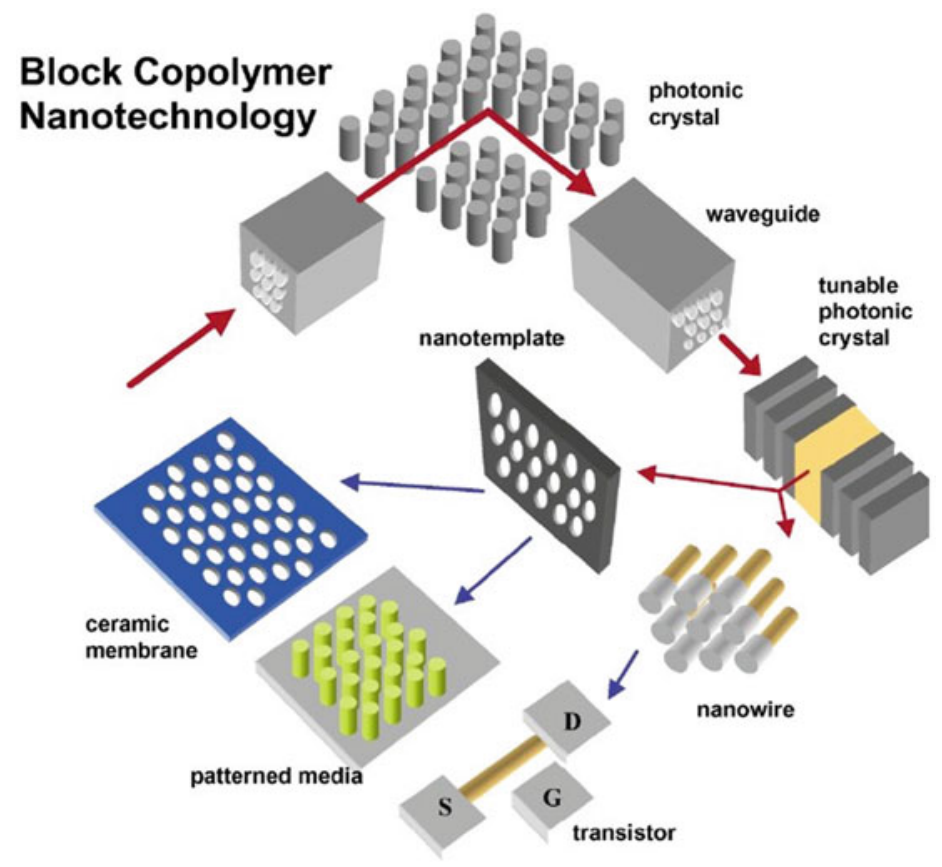

Fig. 4.1 Schematic of various applications of BCPs in nanotechnologies. Reprinted from ref. [8], Polymer 2003, 44, 6725, Copyright 2003, with permission from Elsevier

film morphologies are particularly attractive, presenting high degree of order and uniaxial symmetry: the lamellar phase in parallel (homeotropic) alignment, which constitutes easily produced well-ordered and periodic multilayered slabs, and the phase of hexagonally packed cylinders in perpendicular orientation, from which can be obtained patterns of cylindrical nanodots or nanopores. The latter structures have attracted a lot of attention, with applications including high-density storage media [11, 12], lithographic masks [13-17], nanofluidics [18], separation membranes $[19,20]$, templates for nanorods synthesis [21, 22], enhanced patterned LEDs [23]. As it becomes obvious below, many research efforts have been devoted to the control of this orientation.

Extensive and excellent literature [24, 25], can be found on block copolymers and their microphase separation. After a brief reminder of some necessary bases, we will focus here on the conditions allowing to access specific patterns at the free surface of a thin film. This concerns mostly really thin films, a regime in which the film structure will be strongly affected by its interfaces on the one hand, and by the commensurability of the film thickness $T$ with a (small) integer number of $d_{\mathrm{o}}$, the size of the microphase separation-induced period. This natural nanoscopic dimension $d_{\mathrm{o}}$ constitutes a strong, almost inflexible constraint on the nanostructure of block copolymer materials, whatever their shaping, which will have specific consequences in the case of thin films. 


\subsection{Microphase Separation of Block Copolymers}

Block copolymers are the result of covalently linking two or more polymer chains, each called a block. A diblock copolymer is A-A-...-A-A-B-B-...-B-B or $\mathrm{A}_{n}-\mathrm{B}_{m}$, where the polymerization degrees $n$ and $m$ are typically between 10 and $10^{5}$. The nature of the monomers (A or B) can be chosen within a very wide range of chemical functions, made available by the development of many different synthetic techniques [26]. Thanks to the high degree of control of the copolymer synthesis techniques, block copolymers containing two distinct monomers $\mathrm{A}$ and $\mathrm{B}$ can also have various architectures, such as linear diblock $\left(\mathrm{A}_{n}-\mathrm{B}_{m}\right)$, triblock $\left(\mathrm{A}_{n}-\mathrm{B}_{m}-\mathrm{A}_{n}\right)$, pentablock $\left(\mathrm{A}_{n}-\mathrm{B}_{m}-\mathrm{A}_{p}-\mathrm{B}_{m}-\mathrm{A}_{n}\right)$, multiblock $\left(\mathrm{A}_{n}-\mathrm{B}_{m}\right)_{p}$, and star diblocks $\left(\mathrm{A}_{n}-\mathrm{B}_{m}\right)_{p} X$. With a third ingredient $\mathrm{C}$, linear $\mathrm{A}_{n}-\mathrm{B}_{m}-\mathrm{C}_{p}, \mathrm{~A}_{n}-\mathrm{C}_{m}-\mathrm{B}_{p}$, and $\mathrm{B}_{n}-\mathrm{A}_{m}-\mathrm{C}_{p}$ triblocks, multiblocks $\left(\mathrm{A}_{n}-\mathrm{B}_{m}-\mathrm{C}_{p}-\mathrm{B}_{m}-\mathrm{A}_{n}\right.$, etc. . ) and three-armed stars can be obtained, for instance. For the sake of simplicity, we will focus here on the cases of diblock copolymers, composed of two linear blocks of different chemical nature and linked covalently at one of their extremities. The properties of block copolymers with alternative architectures (multiblocks, branched copolymers, etc.) can be to some extent extrapolated from those of diblocks, although they are not nearly as well understood [24].

In the Flory-Huggins description of polymer melt thermodynamics, the interactions between segments, depending only on the local concentration of the different types of chemical functions, constitute the enthalpy contribution, whereas the entropy is a non-local contribution, depending on the number of allowed conformation of the entire copolymer chains [27, 28]. Entropy is related to elasticity and will be optimized when all tensions are released within the chains.

Most polymers are incompatible with one another and phase separate in a blend. This is also true for the distinct blocks of a block copolymer, but because they are covalently linked, they can segregate only as far as the size of the macromolecule itself: this is called the microphase separation and results in the formation of domains of each block [2, 29, 30], in the melt. They are called microdomains, although they actually present nanoscale dimensions: from a few nanometers to a few hundred nanometers depending mostly on the length of the copolymer chain. This segregation at equilibrium occurs when the enthalpic gain of avoiding contact between incompatible blocks overcomes the associated entropic loss. For a diblock $\mathrm{A}_{n}-\mathrm{B}_{m}$, the two terms in the free energy depend only on the dimensionless Flory-Huggins interaction parameter $\chi$ specific of each monomer pair $(\mathrm{A}, \mathrm{B})$ and characterizing their incompatibility, the total polymerization degree $N=n+m$ and the volume fractions of the blocks $f_{\mathrm{A}}$ and $f_{\mathrm{B}}=1-f_{\mathrm{A}}$. The balance of these two terms in the free energy defines a transition line, similar to the binodal in a blend, called the order-disorder transition (ODT). "Disorder" refers to the homogeneous solid in which all blocks are mixed, when $\chi N$ is small and the entropy wins. Low values of $\chi N$ can be obtained for any $(\mathrm{A}, \mathrm{B})$ pair when $N$ is small; or at high temperature (since $\chi$ decreases when the temperature increases). Inversely, in order to reach high values of $\chi N$ with short polymer 
chains, strong incompatibility (high $\chi$ ) is needed. "Order" refers to the segregated systems, in which the macrodomains form equilibrium organized structures.

In the case of the lamellar phase, the free energy can be approximated to two contributions, the stretching energy and the interfacial energy, respectively:

$$
\frac{F_{\mathrm{L}}}{\mathrm{kT}}=\frac{3}{8}\left(\frac{d}{a N^{1 / 2}}\right)^{2}+\frac{\gamma_{\mathrm{AB}}}{\mathrm{kT}} \Sigma
$$

where the interfacial energy is

$$
\gamma_{\mathrm{AB}}=\mathrm{kT}\left(\frac{\chi}{6}\right)^{1 / 2} a^{-2}
$$

and the total interface area

$$
\Sigma=2 \frac{N a^{3}}{d}
$$

with $a$ the size of one segment of the chain, $d$, the layer thickness. Equating $F_{\mathrm{L}}$ with the disordered copolymer melt free energy $F_{\text {dis }}=f_{\mathrm{A}}\left(1-f_{\mathrm{A}}\right) \chi N$, at the orderdisorder transition (ODT), leads to $\chi N \sim 10$, independently of the chemical details of the considered system. Near this value lies the weak segregation limit, while far above $\chi N=10$ is the strong segregation limit. In this latter regime, the interfaces between microdomains are sharp and well-defined [31].

The morphological phase diagrams of diblock copolymers present four equilibrium symmetries: body-centered cubic array of spherical cores (S-bcc), bicontinuous gyroid $(\mathrm{G})$, hexagonally packed cylinders (C), and lamellae (L), which are selected mostly in relation with the volume fractions of the blocks $f_{\mathrm{A}}$ and $f_{\mathrm{B}}=1-f_{\mathrm{A}}$, due to interfacial curvature effects $[2,29]$. These four phases exhibit long range order of dimension 3,2, 3 and 1 respectively. With $\mathrm{ABC}$ triblocks, a much richer (more than 30) variety of phases [24] can be obtained in the bulk, as for example the striking 2D "knitting pattern" [32] (Fig. 4.2).

When the diblocks are close to being symmetrical $\left(f_{\mathrm{A}} \sim f_{\mathrm{B}} \sim 0.5\right)$, the volumes occupied by both blocks on either sides of the interface are comparable, and the interface tends to be flat. This leads to a lamellar phase composed of a periodic stack of alternating slab-shaped microdomains extending infinitely in two directions. The period $d_{\mathrm{o}}$ of this stack, of the order of twice the extended length of the copolymer chain, correspond to the equilibrium conformation of the macromolecules and can hardly be modified for a given copolymer. This equilibrium period $d_{\mathrm{o}}$ is simply the result of the minimization of Eqs. (1-3), reading [33, 34],

$$
d_{\mathrm{o}}=2 N^{2 / 3} a\left[\frac{1}{3}\left(\frac{\chi}{6}\right)^{1 / 2}\right]^{1 / 3}
$$



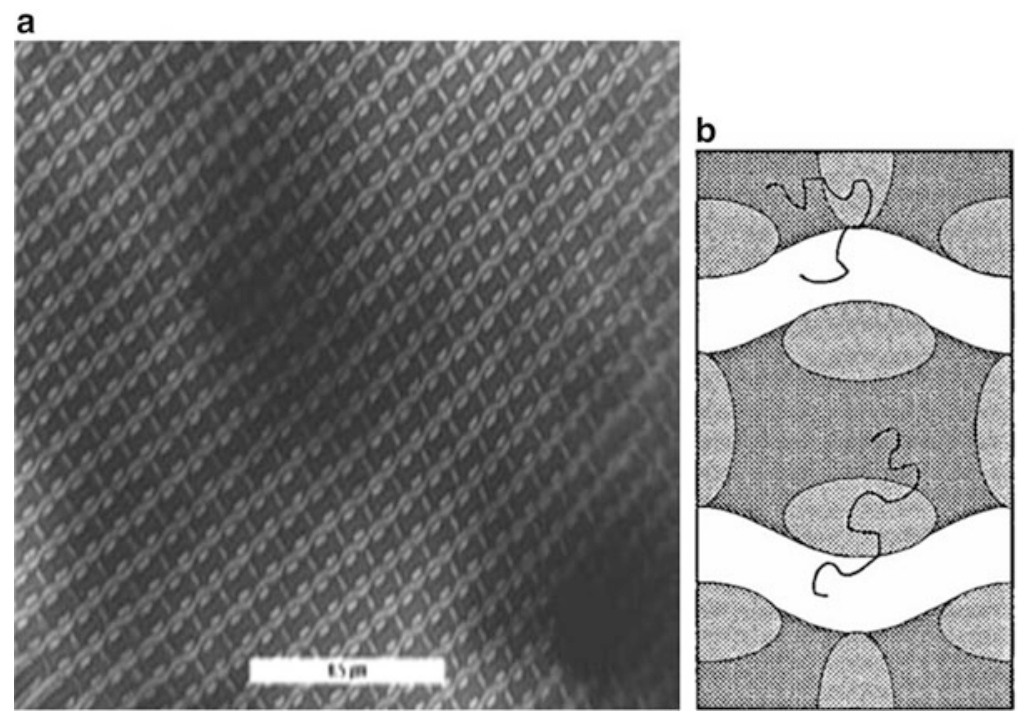

Fig. 4.2 (a) Transmission electron micrograph of a polystyrene-block-poly(ethylene-co-butylene)-block-poly(methyl methacrylate) (SEBM) triblock copolymer, stained with $\mathrm{RuO}_{4}$, presenting the morphology called the "knitting pattern." Bar $=0.5 \mu \mathrm{m}$. (b) Schematic description of the triblock chain conformation within the unit cell. Adapted with permission from ref. [32], Macromolecules 1998, 31, 135. Copyright 1998 American Chemical Society

The easiest way to vary $d_{\mathrm{o}}$ is certainly by changing the total polymerization degree $N$ of the copolymer [35]. But playing with the Flory-Huggins parameter $\chi$, either through temperature [34], or initial monomer choices, or diblock chemical composition is also considered [36]. Typically, $d_{\mathrm{o}}$ is easily obtained between 30 and $120 \mathrm{~nm}$ with commercially available BCPs, while going below $30 \mathrm{~nm}$ or beyond $120 \mathrm{~nm}$ may require tailor-made products.

\subsection{Block Copolymer Thin Films}

As was described before, the equilibrium nanostructures of BCP melt (dry) state are completely controlled by thermodynamics and do not depend on the processing or shaping of a sample. However, the pattern actually exhibited at the surface of a BCP thin film, and the nanostructure organization throughout the thickness of the film, can depend on the shaping and boundary conditions, even at thermodynamic equilibrium. Therefore, the control of orientation of ordered copolymer phases is an important part of the research effort aimed at developing functional surfaces or thin films [37]. This part of the research has benefitted from methodologies adapted from liquid crystal studies, in which the alignment of anisotropic liquids in thin films is required for both fundamental experimental work and applicative developments [38]. 
The equilibrium nanostructures, while presenting a high degree of order, typically extend over the size of grains, like in polycrystalline materials, leading to macroscopic isotropy. This grain size can be enlarged by annealing processes, but the application of external constraints is usually required to access macroscopic samples with no grain boundaries (monocrystals, or fully aligned samples).

In the case of thin films, meaning for thicknesses ranging from one time until typically ten times the equilibrium characteristic size of the nanostructure, surface effects act as efficient external constraints. It is indeed obvious that boundary conditions can influence the orientation of anisotropic materials in the vicinity of the boundaries and this is likely to affect the whole structure when the thickness of a film is small.

Thin films are usually produced by spin-casting from a relatively dilute solution $(<\sim 5 \mathrm{wt} \%)$, or sometimes other casting techniques, and are rarely at equilibrium, due to the fast evaporation of the solvent leaving no time for the macromolecules to adjust their conformations. The copolymer chains are then either fully mixed (the film is said disordered or amorphous) or presenting some kinetically arrested metastable nanostructure [39], depending on the casting solvent (selectivity, saturation vapor pressure) and conditions (concentration, speed, etc). Bringing the film to equilibrium is usually done by thermal or solvent annealing. Elevated temperatures for several hours (above the glass transition temperatures of the constituent blocks and preferably in an inert atmosphere in order to avoid oxidative degradation), or solvent vapor swelling give the chains the necessary mobility for the system to evolve towards the equilibrium nanostructure. This evolution follows the minimization of the system energy, including the terms discussed in Sect. 4.1, leading to the formation of the microphase separated nanostructure, as well as the surface energy at the substrate and atmosphere surfaces. The two blocks, of different chemical nature, usually present a significant contrast in their interfacial energy at the contact of both the substrate and the atmosphere, which will induce a significant energy gain if the right domain is exposed at each interface. In the case of the lamellar structure, this selective alignment at the boundary produces a parallel alignment of the multilayered structure (cf. Fig. 4.3a), which then propagates throughout the thickness of the film.

\subsection{Forcing the Perpendicular Alignment}

As was said before, a strong motivation for reaching perpendicular alignment of nanostructured thin BCP films is the production of nanolithography masks [8, 11 , 40] because they can reach sub-20 nm dimensions, at which classical lithography techniques cannot be applied and sophisticated variations including extreme UV technologies [41] are necessary. BCP are considered an interesting alternative, which motivates many of the research efforts in the search for alignment control. 

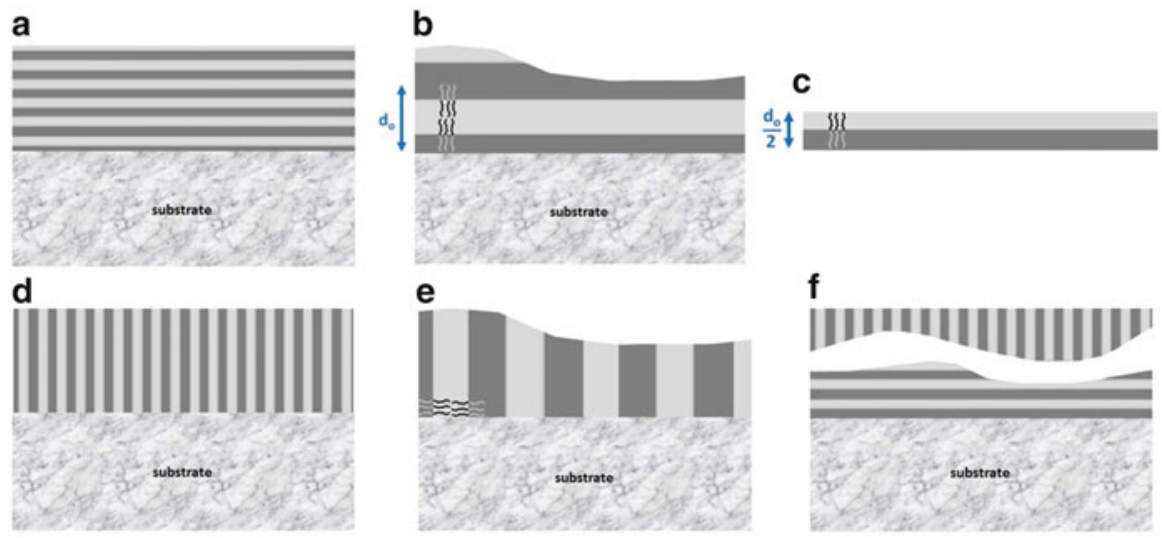

Fig. 4.3 Schematic representation of various alignment situations: (a) and (b) show parallel alignment, (c) represents the elementary brick constituting parallel aligned films, (d) and (e) show perpendicular alignment, (f) shows a mixed alignment

\subsubsection{Surface Energy Tuning}

Rarely occurring naturally, the situation in which the contrast in interfacial energy at the contact of the substrate for the two blocks vanishes, can be induced by a proper surface treatment. This treatment needs to remain unaltered by the thermal or solvent annealing process, which will be used for the alignment step. A clever surface treatment insuring a neutral surface energy towards a given diblock copolymer consists in grafting the substrate with a random copolymer of same chemical composition than the diblock [42, 43], although this may induce interactions between the random brush and the block copolymer film, which go beyond a simple surface energy effect [44]. Other surface treatments can be employed, provided that they can be finely tuned, in order to access the proper balanced energy [45].

When the surface energy is neutral for a given diblock, entropic effects will lead to a perpendicular alignment of the nanostructure, due to a preferential conformation of the macromolecules lying along the substrate surface [46]. The Fig. 4.3d, e sketch successful achievements of perpendicular alignment at the substrate interface. Getting perpendicular alignment at the free surface of the film is more difficult, because most ambient conditions will present a preferential surface energy towards one of the blocks of any diblock. It is therefore common to obtain a hybrid alignment [47] (like shown in the Fig. 4.3f), unless the thickness of the film is restricted to a very small value, in which case geometrical constraints will prevent the deformation of the nanostructure to adjust from one orientation to the other. Hybrid orientation films, however, can be processed, by some etching techniques, in order to reveal the perpendicular pattern. 


\subsubsection{Other Surface Effects}

\subsubsection{Roughness}

The effects of the substrate roughness on the orientation of BCPs in thin films have been studied experimentally [48, 49], and theoretically [50]. Typically, if the roughness characteristic lateral length is larger than the period of the copolymer nanostructure, the favored orientation will always be perpendicular, unless the roughness characteristic height is very small. Provided that the substrate roughness is not detrimental to the final use of the supported film, roughness can be an easy control knob for modifying the alignment of a nanostructured film. For instance, ITO-covered surfaces can be used as electrodes in organic electronic devices and double as conveniently rough surfaces.

\subsubsection{Graphoepitaxy}

Graphoepitaxy consists in using substrates with designed topographic features and was developed as a way to better control the effects of the substrate topography, rather than counting on sometimes ill-defined roughness. Substrates with templating grooves could, for instance, constrain a spherical BCP structure to adopt a highly ordered nanopattern [51, 52], when the template dimension is commensurate with the nanostructure characteristic size. The templates can be produced by "standard" lithography techniques because its dimensions are typically one order of magnitude larger than that of the BCP nanostructure. This combination of top-down (lithographic) technology at $\sim 500 \mathrm{~nm}$ scale and bottom-up (BCP nanostructures) at $\sim 50 \mathrm{~nm}$ scale is promising for well controlled nanosurfaces, if somewhat tedious. Other substrates with specific topographies were successfully used to produce perpendicular alignment of phases of hexagonally packed cylinders: faceted crystals [11] and interferometrically produced sinusoidal polymer gratings [53], are among the interesting examples. The former case proved appropriate for very thin films, whereas the latter requires a thickness above a threshold value of several times the pattern sinusoidal amplitude and the nanostructure period. Provided these structural features are compatible with a given desired structure, and the presence of the groove template is not problematic for the considered applications, these methodologies are interesting.

\subsubsection{Chemically Patterned Surfaces}

Besides topographically patterning the substrate, it can be useful to orient and possibly align PCB thin films with chemically patterned substrates. The propagation of surface patterns into the bulk was predicted to be possible [54], and some of these situations were demonstrated experimentally. For instance, Kim et al. [55] 
Fig. 4.4 Effect of

a chemical pattern on the alignment and azimuthal orientation of lamellar block copolymer nanostructure: top-view SEM images $(2 \mu \mathrm{m} \times 2 \mu \mathrm{m})$ of the nanostructure morphologies of thin films of lamellar copolymer with period $d_{\mathrm{o}}=48 \mathrm{~nm}$ onto chemically patterned substrates as a function of the pattern pitch and the composition of the random copolymer used to create the pattern. Adapted with permission from ref. [56], Adv. Mater. 2004, 16, 1315. Copyright 2004 John Wiley and Sons

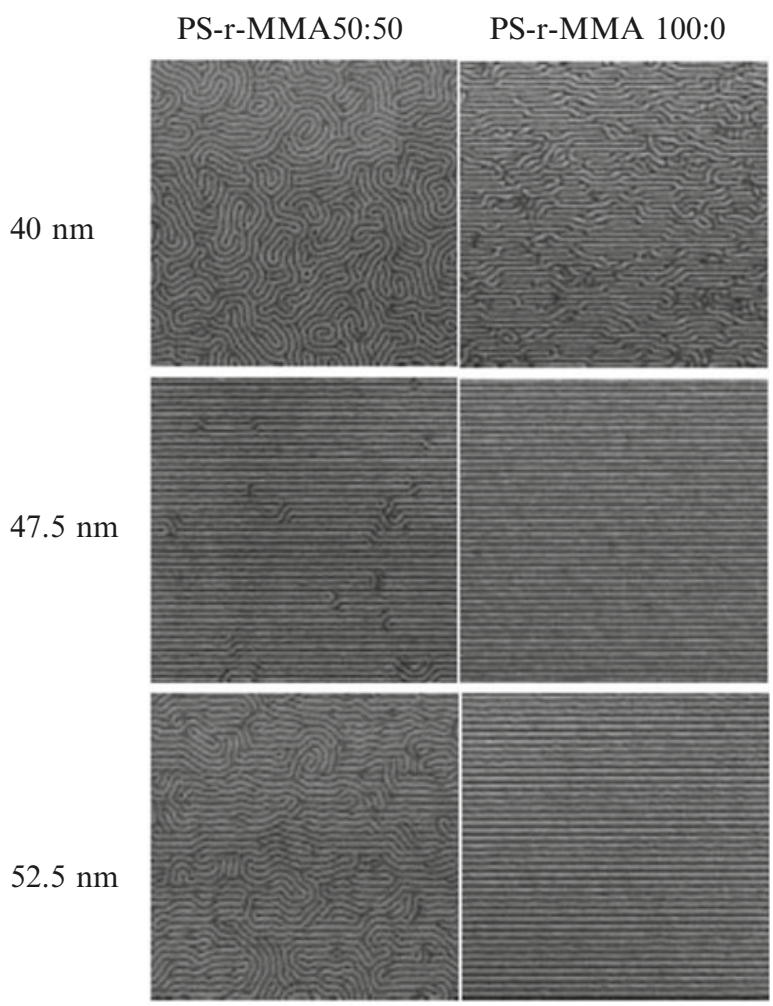

patterned a substrate using extreme ultraviolet interferometric lithography [41] to transfer alternating lines and spaces to a self-assembled monolayer (SAM) and studied the configurations of thin PS-PMMA films on top of such substrates. For this technique, sometimes referred to as epitaxy, commensurability constraints appear severe since the perpendicular alignment of lamellar microdomains by striped patterns can be obtained only with a pattern pitch equal to the BCP lamellar period within less than $5 \%$ mismatch. The registry can have a slightly larger mismatch tolerance if the chemical pattern is produced with a random copolymer brush [56], supposedly because the interpenetration of the brush chains in the BCP film allows some variation of the lamellar period around the equilibrium value $d_{\mathrm{o}}$ (cf. Fig. 4.4). Contrary to the graphoepitaxy patterning, the chemical template must have the same lengthscale than the structure to be aligned, meaning molecular scale, and therefore requires high-tech lithography techniques. This is why, although it is of fundamental interest to show the mechanisms of such alignment, it cannot claim the finality of an easy production of nanoscale patterns.

Real crystalline epitaxy has also been used to align BCP thin films, while using specific interactions between semicrystalline BCPs and crystalline substrates $[57,58]$, or directional crystallization [59]. 


\subsubsection{Solvent Annealing}

The effect of solvent swelling has become increasingly used in the last decade for the manipulation of block copolymer thin film textures. If a block copolymer thin film is swollen with a solvent, which is a true neutral solvent for the copolymer (meaning the affinities of the two blocks are exactly equal), the presence of the solvent will provide mobility to the copolymer chains and allow them to reach the equilibrium structure, then defined, as before, by the balance between conformation, incompatibility and surface energy effects. In that sense, it would usually produce the same effect as a thermal annealing, but specific effects can also be observed due to the evaporation process, like the presence of a solvent concentration gradient normal to the substrate plane and a subsequent ordering front from the film surface to the substrate, which will on the one hand induce a highly directional nanostructure, and on the other hand increase the impact of the interfacial energy conditions at the free surface (where the solvent concentration is the lowest).

In general, however, the solvent used is not genuinely neutral, which would usually lead to kinetically trapped nanostructures and alignments, especially if one or both blocks are glassy at room temperature [60]. Such metastability makes it possible to force the alignment of the nanostructures without tuning the energy balance, and the glassy nature of the final film insures the long-term absence of evolution of the pattern. Solvent swelling was proven to be a useful process to reach perpendicular alignment of cylinders in different systems [61-64] (cf. Fig. 4.5). This process is however still considered difficult to reproduce, mainly because reproducibility requires a precise mastering and controlling of many experimental

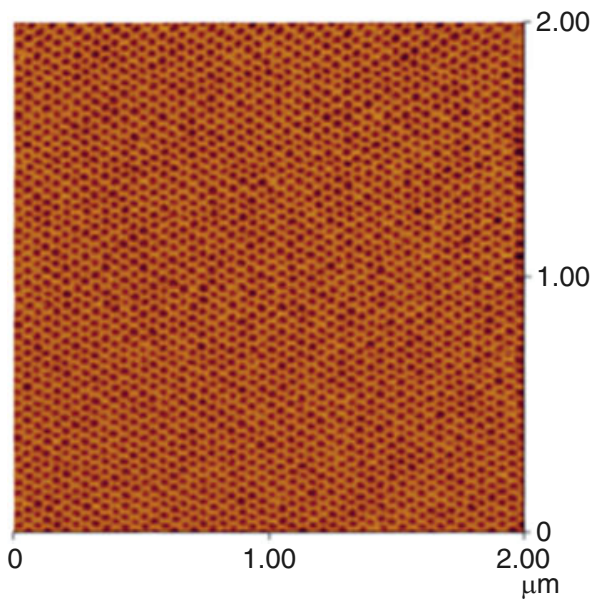

Fig. 4.5 Atomic force microscopy (AFM) phase image of the top surface of a thin film of poly (styrene)-b-poly(oxyethylene) diblock copolymer presenting a phase of hexagonally packed cylinders aligned perpendicular to the substrate after annealing in benzene vapor. The image contrast comes from the difference of elastic modulus between the domains. Adapted with permission from ref. [62], Adv. Mater. 2004, 16, 226. Copyright 2004 John Wiley and Sons 
details besides the choice of the solvent: film thickness [65], annealing time with characteristic times sometimes shorter than 1 min [63], vapor pressure and the rate of vapor removal $[39,66]$, glass transition temperature. All these can affect, often in coupled ways, the resulting metastable morphologies. The effects indeed involve different mechanisms including the modification of the interfacial energies of the swollen film as a function of the solvent loading, as well as hydrodynamic effects [62]. These non-equilibrium processes have not been easily considered by theory, but phase behavior and film patterns could be modeled in great detail by simulations [65] based on dynamic density functional theory. Nevertheless, solvent annealing is one of the most promising method, at this time, for the easy production of large-scale well-aligned nanopatterned thin films of block copolymers, while offering at the same time interesting scientific questions related to these non-equilibrium systems.

\subsubsection{Other Fields}

\subsubsection{Electrical}

The application of an external electric field, adapted from methodologies well optimized for liquid crystal systems, has been used with success [67-69] for large-scale alignment, although it often results in hybrid alignment situations (cf. Fig. 4.6). The electric field effect indeed competes with the surface effects, as was well documented theoretically [70, 71], while also taking into account the effects of mobile charged impurities in the films [72]. The nanostructure development and alignment could be followed by time-resolved X-ray scattering in the cases of initially disordered and ordered films $[69,73]$. The reorientation of ordered films occurs by the fragmentation of the initial nanostructure into small domains, all eventually oriented along the field. The application of the field while the film is swollen by a neutral solvent proved beneficial for large scale alignment, and was satisfactorily described by simulations $[74,75]$.

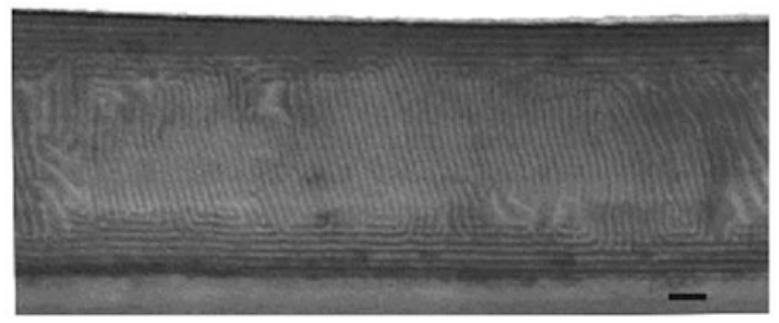

Fig. 4.6 Cross-sectional TEM image of a $\sim 700 \mathrm{~nm}$ PS- $b$-PMMA film annealed under $\sim 40 \mathrm{~V} / \mu \mathrm{m}$ electric field for $16 \mathrm{~h}$. Scale bar: $100 \mathrm{~nm}$. Reprinted with permission from ref. [47], Macromolecules, 2004, 37, 2625. Copyright 2011 American Chemical Society 

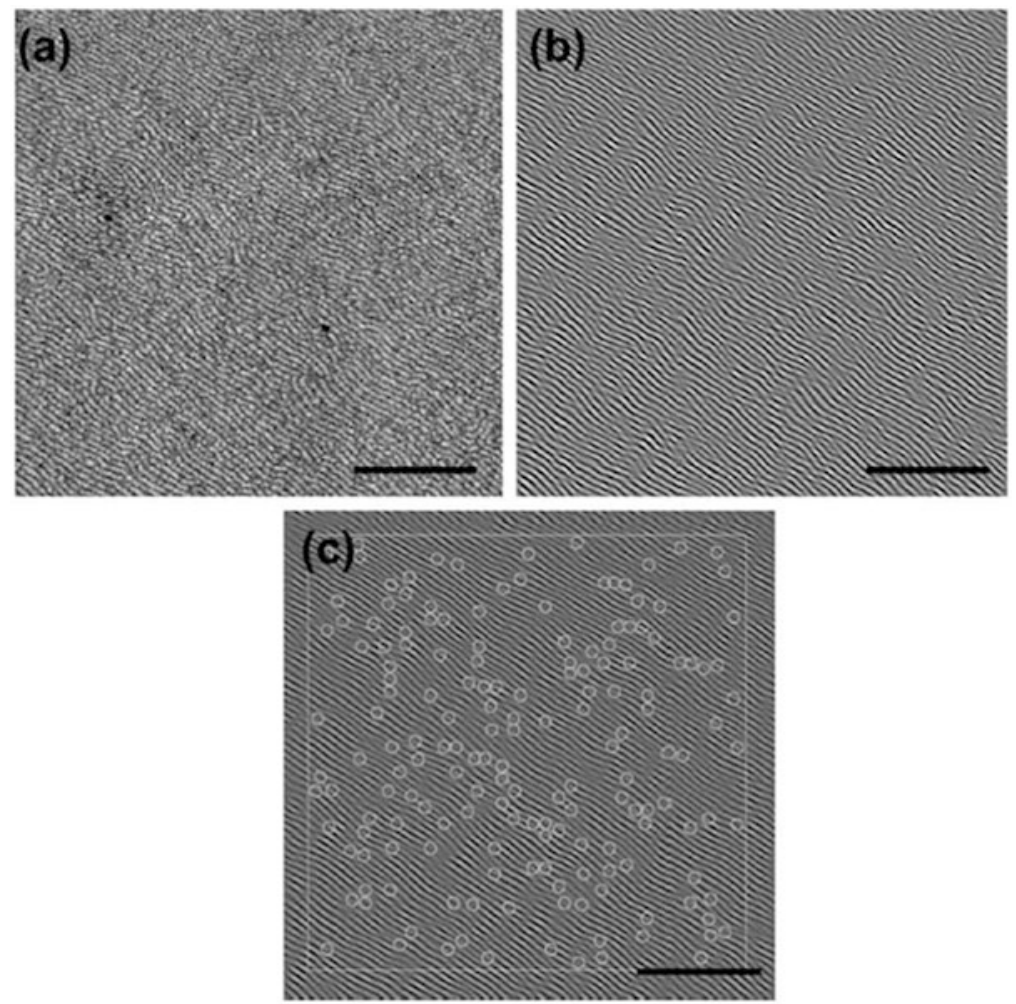

Fig. 4.7 (a) AFM image of a PS-PMMA film, $18 \mathrm{~nm}$ thick, shear-aligned at $40 \mathrm{kPa}$. (b) The same image after being Fourier-filtered. (c) Same image as in (b), with small circles added to mark the dislocation cores identified by an appropriate image treatment algorithm. Scale bars represent $500 \mathrm{~nm}$, and the shear direction is oriented roughly diagonal (upper right to lower left) in all images. Adapted from ref. [81] with permission of The Royal Society of Chemistry

\subsubsection{Flow}

In bulk systems, shear induced alignment has proven the most successful, and has focused large research efforts, both experimentally [76, 77], and theoretically [78], which go beyond the scope of this chapter and are reviewed elsewhere [79]. Shear alignment of thin films was shown to be very efficient on spherical and cylindrical block copolymer phases, if it is performed at a temperature between the highest of the two glass transition temperature and the order-disorder transition temperature of the diblock [80]: $T_{\mathrm{g}}<T<T_{\mathrm{ODT}}$. In other cases, however, a good alignment is obtained with a high defect density [81] (Fig. 4.7).

Other alignment methodologies have been cited [82], including optical alignment of liquid crystalline block copolymers, and temperature gradients [83, 84], but are less general or practical. 


\subsection{Parallel Alignment}

As was explained before, the parallel alignment is most of the time obtained spontaneously. For cylindrical nanostructures, this situation usually exposes at the free surface a homogeneous layer of the preferentially wetting block [85], meaning that here again, an etching step needs to be developed for nanopatterning purposes. For lamellar nanostructures, this alignment does not induce any exposed nanostructure-based pattern at the free surface. However, a complete alignment of the copolymer film (shown in Fig. 4.3a) is only possible if the total thickness of the film is commensurate with the lamellar period: $T=n d_{\mathrm{o}}$ or $T=(n+1 / 2) d_{\mathrm{o}}$, where $n$ is usually a small integer $(1 \leq n \leq 8)$. The reason for that is that due to the free energy constraints on both the nanostructure alignment and the copolymer chain conformations, the nanostructured film has to be built as an assembly of the elementary brick (shown in Fig. 4.3c) composed of a copolymer layer of thickness $d_{\mathrm{o}} / 2$, corresponding to half of a bilayer of size $d_{\mathrm{o}}$, the lamellar period. When deposited by a given casting technique, the film has a thickness controlled by the parameters of the casting (initial concentration and rotation speed and acceleration, for example in the case of spin-coating). While the fine tuning of these parameters, and therefore of the final film thickness, is in principle possible, it is more common to obtain a film with a thickness not exactly equal to $n d_{\mathrm{o}}$ or $(n+1 / 2) d_{\mathrm{o}}$. The layered structure of the copolymer then forces the film to present regions of different thicknesses, with the different regions satisfying one of the commensurability conditions [86, 87]. The film is therefore terraced, with a quantized surface topography: the step height of the terraces is $d_{\mathrm{o}}$, so that the free surface exposes the same block domain on each terrace.

When the film thickness is close to and below the commensurability condition, the film lacks a little matter to reach a flat surface, and the terraces are shaped as holes, whereas when the film thickness is close to and above the commensurability condition, the film has a small excess of matter to reach a flat surface, and the terraces are shaped as islands [88]. This evolution is very obvious when a thickness gradient is produced on a lamellar copolymer thin film, as shown in Fig. 4.8. Interestingly, the film is flat on a finite range of thickness around the commensurability condition, showing that the copolymer layers are able to slightly adjust their surface chain density, so that the film can accommodate small discrepancies in thickness and avoid the cost of building a terrace edge.

The edges of the terraces concentrate the excess free energy related to a structural defect in the lamellar organization. These defect lines were shown to have a specific dynamics [89] and to present apparently stable structures [90], for some conditions of film $T$ and bilayer $d_{\mathrm{o}}$ thicknesses. This allows for the relatively easy achievement of specific patterns, with a length scale one or two orders of magnitude larger than that of the copolymer nanostructure. Moreover, Li et al. have shown that these patterns can be somehow manipulated [91] as they present registry or anti-registry with underlying topographically patterned surfaces. 

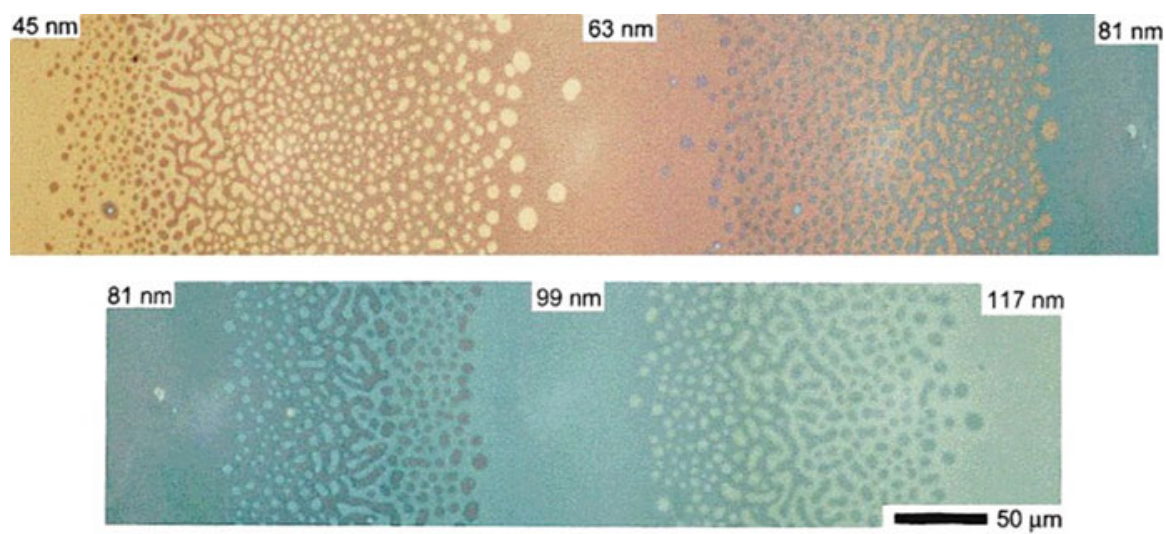

Fig. 4.8 True color optical micrograph of a continuous 26k PS-b-PMMA film with thickness gradient. The lower section is a continuation of the upper section. Film was annealed for $6 \mathrm{~h}$ at $170{ }^{\circ} \mathrm{C}$, and the image shows the addition of four successive lamellae to the block copolymer film with increasing thickness, and the corresponding terraced patterns. Labels indicate when the film thickness verifies $h_{\mathrm{s}}=(n+1 / 2) d_{\mathrm{o}}$, where $n=2-6$. Reprinted with permission from ref. [88], J. Polym. Sci.: Part B: Polym. Phys. 2001, 39, 2141. Copyright 2001 John Wiley and Sons

\subsection{In-Plane Degeneracy and Single-Grain Formation}

Beyond the formation of a specific alignment with regards to the substrate plane, ensuring the formation of a single-grain BCP lattice on large areas is critical in many cases. Also, in the cases of parallel oriented cylinders and perpendicular oriented lamellae, the orientation of the domains is azimuthally degenerate, and a complete in-plane alignment of the structure, usually desired in view of applications such as interconnects or light polarizers, requires some additional action.

An additional field can be applied orthogonally, which can be again of different nature. For instance, nicely ordered lamellar microdomains have been obtained by the combined application of a electric field and a flow field in a rather thick film [92]. Temperature treatment can also be combined with shear [93]. A combination of static and dynamic effects was successfully applied by Berry et al. [94], who used a graphoepitaxy and dynamic thermal annealing.

An intrinsically directional single field can align BCP patterns. As was mentioned before, chemically patterned surfaces, having the same length scale as the BCP nanostructure, apply a strong constrain on BCP thin films. It was shown to actually induce unidirectional orientation of perpendicular aligned lamellar phases $[55,56]$. Graphoepitaxy alone can also unidirectionally align line patterns and organize spherical domains. Use of faceted surfaces [95] and 1D groove templates [52], due to entropic effects, as well as nanoimprint lithography [96, 97] (NIL), due to surface effects on the vertical groove walls, are efficient techniques to orient BCP nanostructures without requiring macromolecule-scale prior patterning. In the case of reconstructed sapphire surfaces, the atomic crystalline ordering of the 

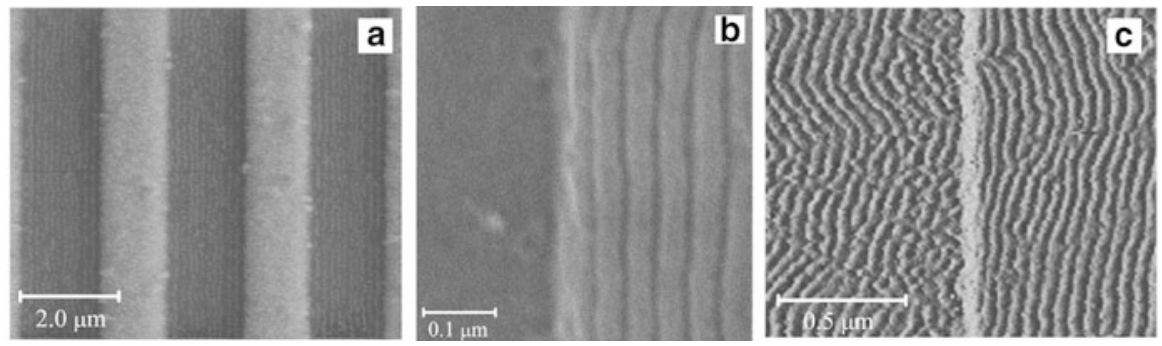

Fig. 4.9 (a) Top view of a SEM image of the BCP film after nanoimprinting with a NIL mold with main pitch $1.5 \mu \mathrm{m}$. The groove height is $50 \mathrm{~nm}$. The perpendicularly lying BCP lamellae are further oriented along the groove long axis. (b) An enlargement of (a) where several lamellae (left) are well ordered in-plane. (c) An AFM top view of an enlarged section of the BCP film close to thin-thick boundary (the middle vertical line). To the right, the BCP film is thicker and is ordered by the groove vertical wall, whereas to the left, the BCP is thinner and less ordered. Reprinted with permission from ref. [96], Macromolecules, 2011, 44, 2206. Copyright 2011 American Chemical Society

substrate can be transferred, over multiple length scales, to the block copolymer microdomains, via facets regular pattern. In the latter case, a micrometer-sized carved mold is imprinted onto the film, in order to guide the self-assembly of the BCP at the nanometer scale (cf. Fig. 4.9). Self-consistent field theory successfully accounted for the experimental results on NIL azimuthal alignment of lamellar domains, as shown in ref. [96].

Recent progress in the generation of large single-grain BCP thin films include zone processing, which induces sharp ordering front able to guide self-assembly (cf. Fig. 4.10). This can be found in a number of variations, like zone casting, using a scanning polymer deposition process [98], raster solvent vapor annealing [99], generating a localized solvent annealing zone with a scanning solvent vapor delivery nozzle, or thermal gradient zone processing [93, 100].

Device-oriented structures like sharp corners and curved patterns can be transferred into the BCP pattern [101]. In these studies, a small quantity of compatible homopolymer was added to the copolymer, which can redistribute in locations where it will compensate the mismatch between the pattern pitch and the natural lamellar domain $d_{\mathrm{o}}$, thus allowing the copolymer pattern to follow even the sharp features of the underlying guide (cf. Fig. 4.11).

\subsection{Experimental Techniques for the Structural Studies of the Nanopatterns}

Atomic force microscopy (AFM) is a very useful technique to study the patterns exhibited at the surface of thin films. Used in taping mode, which exploits the interaction of the tip with the surface during intermittent contacts between 

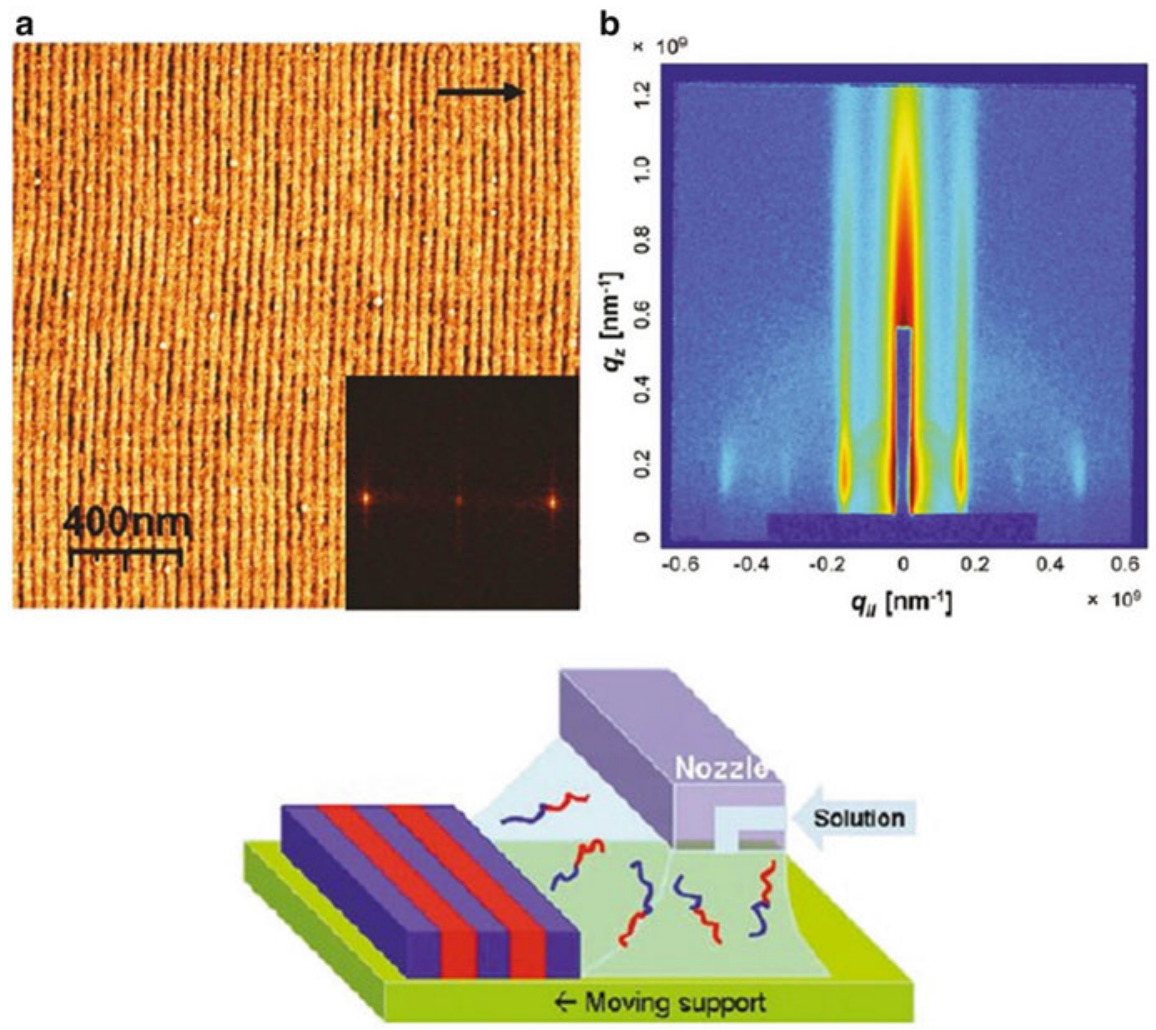

Fig. 4.10 Zone casting of a lamellar BCP thin film. (a) Taping mode AFM phase image (inset: FT transform), and (b) GISAXS pattern of PODMA- $b$-PtBA- $b$-PODMA block copolymer films prepared by zone casting at $40{ }^{\circ} \mathrm{C}$. Arrow: substrate withdrawal direction. (c) Scheme of the zone casting technique. Adapted with permission from ref. [98], J. Am. Chem. Soc. 2011, 133, 11802. Copyright 2011 American Chemical Society

them, this scanning microscopy technique can provide topographic images of the free surface with a resolution allowing the observation of $10 \mathrm{~nm}$ features or sometimes less, but it can also provide images of chemical contrast between microdomains. Phase images, in particular, relate to the damping of the tip oscillations, which varies with the local elasticity and more generally with the type of tip-polymer interactions at play. This is very complementary to topographic images, specifically because the nanopatterns of block copolymers may sometimes coexist with relatively flat and smooth surfaces. AFM cannot report on in-depth nanostructure but is well suited for studies of top surface patterns and their evolution upon annealing. Defect mobility and annihilation can be imaged, for instance [102] as is shown on Fig. 4.12.

As for other organized soft matter systems with nanoscale characteristic sizes, $X$-ray and neutrons scattering techniques are very appropriate for the study of block 

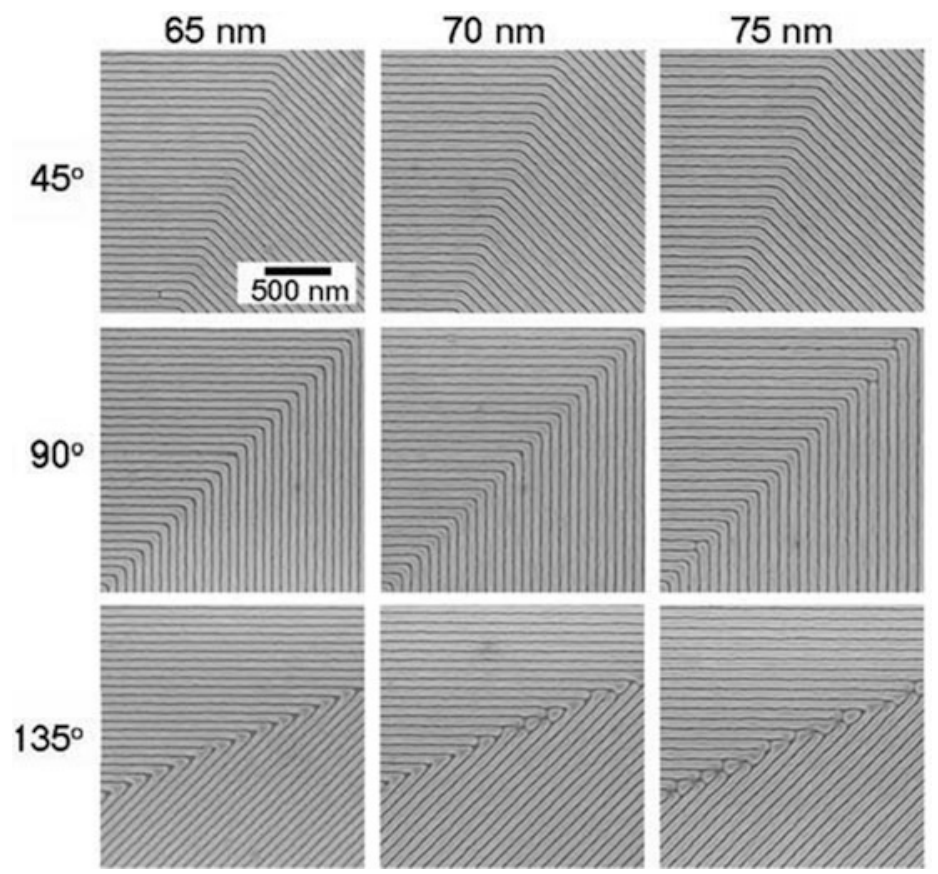

Fig. 4.11 Effect of a chemical pattern on the azimuthal orientation of lamellar block copolymer lamellar nanostructure: top-view SEM images $(2 \mu \mathrm{m} \times 2 \mu \mathrm{m})$ of the nanostructure morphologies of thin films of lamellar copolymer with period $d_{\mathrm{o}}=70 \mathrm{~nm}$ onto chemically patterned substrates with a bent of $45^{\circ}, 90^{\circ}$, and $135^{\circ}$ as a function of the pattern pitch. Adapted from ref. [101]
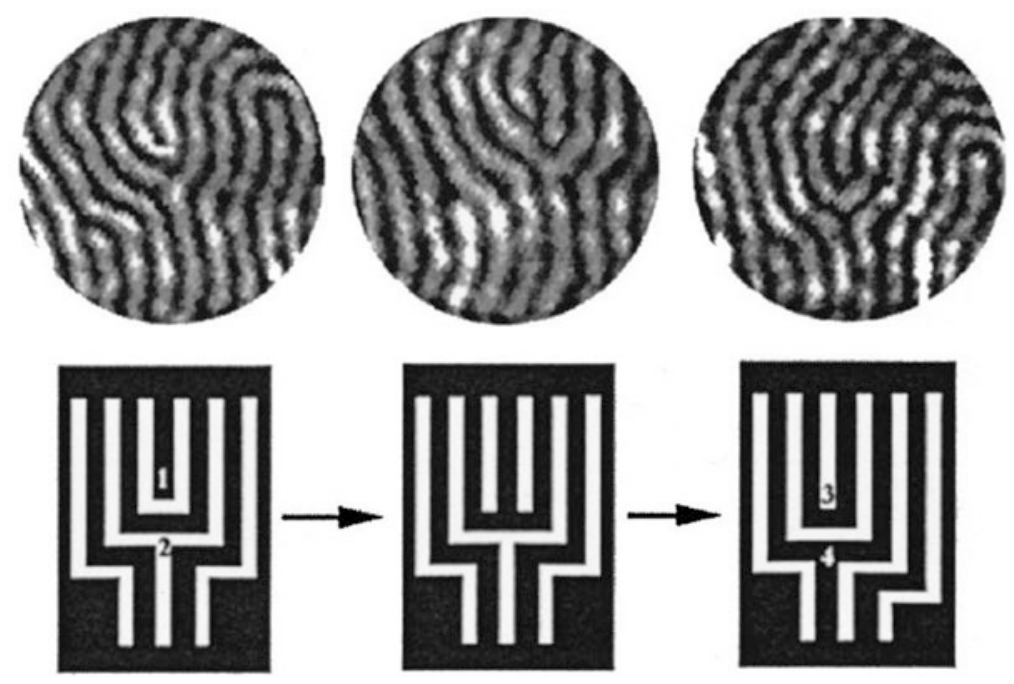

Fig. 4.12 AFM images taken between repeated annealing treatments of a further hour at $523 \mathrm{~K}$ showing the evolution of a disclination pair. In each image, the repeat spacing of the microdomains is $50 \mathrm{~nm}$. Adapted with permission from ref. [102], J. Chem. Phys. 2001, 114, 4730. Copyright 2001 AIP Publishing LLC 
copolymer self-assembled nanostructures. In the case of thin films, two main experimental configurations are of interest: the reflectivity [103] and the smallangle scattering at grazing incidence (GISAXS) [104-106]. These techniques provide a large foot-print of the beam on the samples, allowing the collection of data in spite of the sometimes minute thickness of the films. Reflectivity is sensitive to the ordering along the film normal, and is well adapted for layered films. It can also efficiently quantify roughness. GISAXS measures the off-specular signal and records both in-plane and out-of-plane order, giving access to the in-depth nanostructure. It presents a very good temporal resolution, allowing following in detail the nanostructure evolutions during solvent or thermal treatments.

Spectroscopic ellipsometry is an elaborate technique, which has been used as a robust and extremely sensitive tool for material characterization [107]. During the last decade, its domain of application has been extended to the study of nanostructured samples, although it is mostly appropriate for the determination of order along the film normal. Small refractive index contrast multilayer structures and birefringence can be experimentally accessed [108] in some conditions, but may require sophisticated models.

Emerging new methods include resonant X-ray scattering [109], for enhanced contrast, critical-dimension SAXS, giving access to a 3D reconstruction [110] of in-depth structural features in the films, and scattering infrared near-field microscopy [111], for nanoscale chemical analysis at surfaces.

\subsection{Perspectives}

Macroscopically aligned BCP thin films provide invaluable robust, versatile, chemically functionalizable nanopatterned surfaces. Due to the interplay between film thickness, nanostructure and alignment, careful and complex processes are required to reach large scale alignment monodomains. Moreover, with the multiplication of the actual possibilities in term of copolymer architecture, monomer choices, advanced substrates, high-tech deposition and treatment processes, as well as new time- or spatially resolved analysis techniques, the field of nanopatterned BCP thin films is still ready to provide remarkable model study subjects as well as routes for defect-free or tailor-made nanomaterials for technological applications.

Device-oriented structures with complex patterns will be obtained by the design and juxtaposition of guiding tiles on the substrates, as has been done by Chang et al. [112], who achieved patterns including dense bends, junctions, and lines with a simple and predictable topographic template (cf. Fig. 4.13).

Search for ever-smaller characteristic sizes, in order to reach the sub-20 nm limits desired for lithography applications, has involved the choices of new monomer combinations [13,113], salt complexation [114], and exploration of the weak segregation regime [115]. However, this goal is conflicting with the need for defectfree patterns, since the energy cost of a defect formation typically scales as the third 


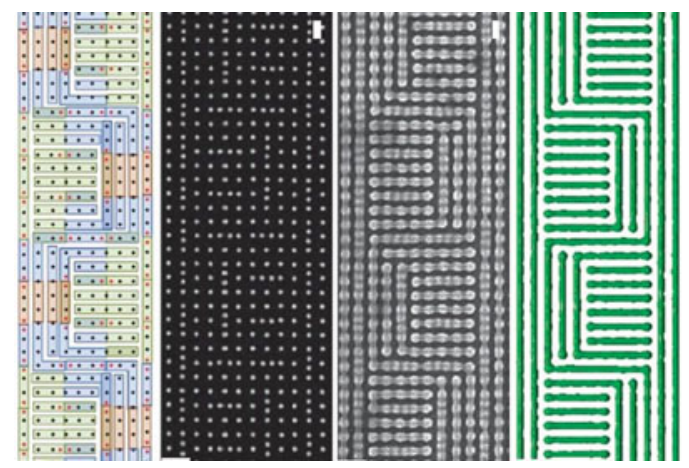

Fig. 4.13 From left to right: template layout to fabricate complex patterns consisting of design patterns of posts. Each color represents the pattern templated by each arrangement; SEM images of the templates of posts to fabricate dense patterns of bends and terminations; SEM images of the PDMS patterns formed on the template shown on the left; SCFT simulation result showing the constant $50 \%$ density surface of PDMS cylinders assembled with the template on the left. Scale bars are $50 \mathrm{~nm}$. Adapted by permission from Macmillan Publishers Ltd: Nature Comm. 2014, 5, 3305 (ref. [112]), copyright 2014

power of the nanostructure characteristic size [116]. Future research effort will be necessary to reach beyond this irreconcilability.

Other expected further studies will likely assess the nanopatterns and the mechanisms of their formation, in thin films of block copolymers with more complex architectures. For instance, the phase behavior of star copolymers is increasingly well described [117]. For enlarging the application openings, more advanced substrates will likely be implemented, like the curved surfaces theoretically considered in recent studies [118, 119]. Efforts will be devoted to the generation of reconfigurable and responsive surfaces, which can adapt to surrounding environments [120], as for instance thermoresponsive nanopatterned surfaces [121].

\section{References}

1. Swarc, M., Levy, M., Milkovich, R.: Polymerization initiated by electron transfer to monomer. A new method of formation of block polymers. J. Am. Chem. Soc. 78, 2656 (1956)

2. Matsen, M.W., Bates, F.S.: Unifying weak- and strong-segregation block copolymer theories. Macromolecules 29, 1091 (1996)

3. Taton, D., Gnanou, Y.: Guidelines for synthesizing block copolymers. In: Lazzari, M., Liu, G., Lecommandoux, S. (eds.) Block Copolymers in Nanoscience. Wiley, Weinheim (2006)

4. Harrison, C., Park, M., Register, R., Adamson, D., Mansky, P., Chaikin, P.: Method of nanoscale patterning and products made thereby. US Patent 5,948,470, 7 Sept 1999

5. Russell, T.P.: Copolymers at surfaces and interfaces. Curr. Opin. Colloid Interface Sci. 1, 107 (1996) 
6. Granick, S., Kumar, S.K., Amis, E.J., Antonietti, M., Balazs, A.C., Chakraborty, A.K., Grest, G.S., Hawker, C., Janmey, P., Kramer, E.J., Nuzzo, R., Russell, T.P., Safinya, C.R.: Macromolecules at surfaces: research challenges and opportunities from tribology to biology. J. Polym. Sci. B Polym. Phys. 41, 2755 (2003)

7. Bucknall, D.G.: Influence of interfaces on thin polymer film behaviour. Prog. Mater. Sci. 49, 713 (2004)

8. Park, C., Yoon, J., Thomas, E.L.: Enabling nanotechnology with self assembled block copolymer patterns. Polymer 44, 6725 (2003)

9. Kim, J.K., Yang, S.Y., Lee, Y., Kim, Y.: Functional nanomaterials based on block copolymer self-assembly. Prog. Polym. Sci. 35, 1325 (2010)

10. Crossland, E.J.W., Nedelcu, M., Ducati, C., Ludwigs, S., Hillmyer, M.A., Steiner, U., Snaith, H.J.: Block copolymer morphologies in dye sensitized solar cells: probing the photovoltaic structure-function relation. Nano Lett. 9, 2813 (2009)

11. Park, S., Lee, D.H., Xu, J., Kim, B., Hong, S.W., Jeong, U., Xu, U.T., Russell, T.P.: Macroscopic 10-terabit-per-square-inch arrays from block copolymers with lateral order. Science 323, 1030 (2009)

12. Ross, C.A., Cheng, J.Y.: Patterned magnetic media made by self-assembled block-copolymer lithography. MRS Bull. 33, 838 (2008)

13. Kennemur, J.G., Yao, L., Bates, F.S., Hillmyer, M.A.: Sub-5 nm domains in ordered poly(cyclo-hexylethylene)-blockpoly(methyl methacrylate) block polymers for lithography. Macromolecules 47, 1411 (2014)

14. Tang, C., Hur, S., Stahl, B.C., Sivanandan, K., Dimitriou, M., Pressly, E., Fredrickson, G.H., Kramer, E.J., Hawker, C.J.: Thin film morphology of block copolymer blends with tunable supramolecular interactions for lithographic applications. Macromolecules 43, 2880 (2010)

15. Park, M., Harrison, C., Chaikin, P.M., Register, R.A., Adamson, D.H.: Block copolymer lithography: periodic arrays of similar to $10^{11}$ holes in 1 square centimeter. Science 276, 1401 (1997)

16. Harrison, C., Park, M., Chaikin, P.M., Register, R.A., Adamson, D.H.: Lithography with a mask of block copolymer microstructures. J. Vac. Sci. Technol. B 16, 544 (1998)

17. Lammertink, R.G.H., Hempenius, M.A., van den Enk, J.E., Chan, V.Z.H., Thomas, E.L., Vancso, G.J.: Nanostructured thin films of organic-organometallic block copolymers: one-step lithography with poly(ferrocenylsilanes) by reactive ion etching. Adv. Mater. 12, 98 (2000)

18. Jiang, Y., Liu, N., Guo, W., Xia, F., Jiang, L.: Highly-efficient gating of solid-state nanochannels by DNA supersandwich structure containing ATP aptamers: a nanofluidic IMPLICATION logic device. J. Am. Chem. Soc. 134, 15395 (2012)

19. Yang, S.Y., Ryu, I., Kim, H.Y., Kim, J.K., Jang, S.K., Russell, T.P.: Nanoporous membranes with ultrahigh selectivity and flux for the filtration of viruses. Adv. Mater. 18, 709 (2006)

20. Phillip, W.A., O’Neill, B., Rodwogin, M., Hillmyer, M.A., Cussler, E.L.: Self-assembled block copolymer thin films as water filtration membranes. ACS Appl. Mater. Interfaces 2, 847 (2010)

21. Kwon, S., Shim, M., Lee, J.I., Lee, T.-W., Cho, K., Kim, J.K.: Ultrahigh density array of CdSe nanorods for CdSe/polymer hybrid solar cells: enhancement in short-circuit current density. J. Mater. Chem. 21, 12449 (2011)

22. Lee, J.I., Cho, S.H., Park, S.-M., Kim, J.K., Kim, J.K., Yu, J.-W., Kim, Y.C., Russell, T.P.: Highly aligned ultrahigh density arrays of conducting polymer nanorods using block copolymer templates. Nano Lett. 8, 2315 (2008)

23. Alam, M.M., Lee, Y.-R., Kim, J.-Y., Jung, W.-G.: Variety of nanopatterns on different substrates using PS-b-PMMA and their applications. J. Nanosci. Nanotechnol. 12, 1634 (2012)

24. Bates, F.S., Fredrickson, G.H.: Block copolymers-designer soft materials. Phys. Today 52(2), 32 (1999) 
25. Hamley, I.W.: The Physics of Block Copolymers. Oxford Science, Oxford (1998)

26. Matyjaszewski, K.: Advances in controlled/living radical polymerization. ACS Series 854, K. Matyjaszewski Ed., 2003, 1 and special issue "Frontiers in Polymer Chemistry". Chem. Rev. 101, 3579 (2001)

27. Matsen, M.W.: The standard gaussian model for block copolymer melts. J. Phys. Condens. Matter. 14, 21 (2002)

28. de Gennes, P.-G.: Scaling Concepts in Polymer Physics. Cornell University Press, Ithaca, NY (1979)

29. Bates, F.S., Fredrickson, G.H.: Block copolymer thermodynamics: theory and experiment. Annu. Rev. Phys. Chem. 41, 525 (1990)

30. Lodge, T.P.: Block copolymers: past successes and future challenges. Macromol. Chem. Phys. 204, 265 (2003)

31. Broseta, D., Fredrickson, G.H., Helfand, E., Leibler, L.: Molecular weight and polydispersity effects at polymer-polymer interfaces. Macromolecules 23, 132 (1990)

32. Breiner, U., Krappe, U., Thomas, E.L., Stadler, R.: Structural characterization of the "knitting pattern" in polystyrene-block-poly(ethylene-co-butylene)-block-poly(methyl methacrylate) triblock copolymers. Macromolecules 31, 135 (1998)

33. Semenov, A.N.: Contribution to the theory of microphase layering in block-copolymer melts. Sov. Phys. JETP 61, 733 (1985)

34. Ren, Y., Lodge, T.P., Hillmyer, M.A.: Effect of selective perfluoroalkylation on the segregation strength of polystyrene-1,2-polybutadiene block copolymers. Macromolecules 35, 3889 (2002)

35. Hashimoto, T.: Generalized view of molecular weight dependence of microdomain size of block polymers. Appraisal of Hadziioannou-Skoulios' data on binary mixtures of block polymers. Macromolecules 15, 1548 (1982)

36. Bendejacq, D., Ponsinet, V., Joanicot, M., Vacher, A., Airiau, M.: Chemical tuning of the microphase separation in diblock copolymers from controlled radical polymerization. Macromolecules 36, 7289 (2003)

37. Lazzari, M., DeRosa, C.: Methods for the alignment and the large-scale ordering of block copolymer morphologies. In: Lazzari, M., Liu, G., Lecommandoux, S. (eds.) Block Copolymers in Nanoscience. Wiley, Weinheim (2006)

38. de Gennes, P.-G., Prost, J.: The Physics of Liquids Crystals. Oxford University Press, New York, NY (1993)

39. Kim, G., Libera, M.: Kinetic constraints on the development of surface microstructure in SBS thin films. Macromolecules 31, 2670 (1998)

40. Black, C.T., Ruiz, R., Breyta, G., Cheng, J.Y., Colburn, M.E., Guarini, K.W., Kim, H.-C., Zhang, Y.: Polymer self assembly in semiconductor microelectronics. IBM J. Res. Dev. 51, 605 (2007)

41. Solak, H.H., David, C., Gobrecht, J., Golovkina, V., Cerrina, F., Kim, S.O., Nealey, P.F.: Sub-50 nm period patterns with EUV interference lithography. Microelectron. Eng. 67-8, 56 (2003)

42. Mansky, P., Liu, Y., Huang, E., Russell, T.P., Hawker, C.J.: Controlling polymer-surface interactions with random copolymer brushes. Science 275, 1458 (1997)

43. Huang, E., Russell, T.P., Harrison, C., Chaikin, P.M., Register, R., Hawker, C.J., Mays, J.W.: Using surface active random copolymers to control the domain orientation in diblock copolymer thin films. Macromolecules 31, 7641 (1998)

44. Han, E., Stuen, K.O., La, Y.-H., Nealey, P.F., Gopalan, P.: Effect of composition of substratemodifying random copolymers on the orientation of symmetric and asymmetric diblock copolymer domains. Macromolecules 41, 9090 (2008)

45. Liu, P.-H., Thebault, P., Guenoun, P., Daillant, J.: Easy orientation of diblock copolymers on self-assembled monolayers using UV irradiation. Macromolecules 42, 9609 (2009)

46. Khanna, V., Cochran, E.W., Hexemer, A., Stein, G.E., Fredrickson, G.H., Kramer, E.J., Li, X., Wang, J., Hahn, S.F.: Effect of chain architecture and surface energies on the ordering 
behavior of lamellar and cylinder forming block copolymers. Macromolecules 39, 9346 (2006)

47. Xu, T., Zhu, Y., Gido, S.P., Russell, T.P.: Electric field alignment of symmetric diblock copolymer thin films. Macromolecules 37, 2625 (2004)

48. Sivaniah, E., Hayashi, Y., Iino, M., Hashimoto, T., Fukunaga, K.: Observation of perpendicular orientation in symmetric diblock copolymer thin films on rough substrates. Macromolecules 36, 5894 (2003)

49. Sivaniah, E., Matsubara, S., Zhao, Y., Hashimoto, T., Fukunaga, K., Kramer, E.J., Mates, T. E.: Symmetric diblock copolymer thin films on rough substrates: microdomain periodicity in pure and blended films. Macromolecules 41, 2484 (2008)

50. Tsori, Y., Andelman, D.: Parallel and perpendicular lamellae on corrugated surfaces. Macromolecules 36, 8560 (2003)

51. Segalman, R.A., Yokoyama, H., Kramer, E.J.: Graphoepitaxy of spherical domain block copolymer films. Adv. Mater. 13, 1152 (2001)

52. Cheng, J.Y., Mayes, A.M., Ross, C.A.: Nanostructure engineering by templated selfassembly of block copolymers. Nat. Mater. 3, 823 (2004)

53. Aissou, K., Shaver, J., Fleury, G., Pécastaings, G., Brochon, C., Navarro, C., Grauby, S., Rampnoux, J.-M., Dilhaire, S., Hadziioannou, G.: Nanoscale block copolymer ordering induced by visible interferometric micropatterning: a route towards large scale block copolymer 2D crystals. Adv. Mater. 25, 213 (2013)

54. Tsori, Y., Andelman, D.: Diblock copolymer ordering induced by patterned surfaces above the order-disorder transition. Macromolecules 34, 2719 (2001)

55. Kim, S.O., Solak, H.H., Stoykovich, M.P., Ferrier, N.J., de Pablo, J.J., Nealey, P.F.: Epitaxial self-assembly of block copolymers on lithographically defined nanopatterned substrates. Nature 424, 411 (2003)

56. Edwards, E.W., Montague, M.F., Solak, H.H., Hawker, C.J., Nealey, P.F.: Precise control over molecular dimensions of block-copolymer domains using the interfacial energy of chemically nanopatterned substrates. Adv. Mater. 16, 1315 (2004)

57. De Rosa, C., Park, C., Lotz, B., Fetters, L.J., Wittman, J.C., Thomas, E.L.: Control of molecular and microdomain orientation in a semicrystalline block copolymer thin film by epitaxy. Macromolecules 33, 4871 (2000)

58. De Rosa, C., Park, C., Lotz, B., Thomas, E.L.: Microdomain patterns from directional eutectic solidification and epitaxy. Nature 405, 433 (2000)

59. Park, C., De Rosa, C., Thomas, E.L.: Large area orientation of block copolymer microdomains in thin films via directional crystallization of a solvent. Macromolecules 34, 2602 (2001)

60. Xuan, Y., Peng, J., Cui, L., Wang, H., Li, B., Han, Y.: Morphology development of ultrathin symmetric diblock copolymer film via solvent vapor treatment. Macromolecules 37, 7301 (2004)

61. Fukunaga, K., Elbs, H., Magerle, R., Krausch, G.: Large-scale alignment of ABC block copolymer microdomains via solvent vapor treatment. Macromolecules 33, 947 (2000)

62. Kim, S.H., Misner, M.J., Xu, T., Kimura, M., Russell, T.P.: Highly oriented and ordered arrays from block copolymers via solvent evaporation. Adv. Mater. 16, 226 (2004)

63. Yin, J., Yao, X., Liou, J.-Y., Sun, W., Sun, Y.-S., Wang, Y.: Membranes with highly ordered straight nanopores by selective swelling of fast perpendicularly aligned block copolymers. ACS Nano 7, 9961 (2013)

64. Bang, J., Kim, S.H., Drockenmuller, E., Misner, M.J., Russell, T.P., Hawker, C.J.: Defectfree nanoporous thin films from ABC triblock copolymers. J. Am. Chem. Soc. 128, 7622 (2006)

65. Knoll, A., Horvat, A., Lyakhova, K.S., Krausch, G., Sevink, G.J.A., Zvelindovsky, A.V., Margele, R.: Phase behavior in thin films of cylinder-forming block copolymers. Phys. Rev. Lett. 89, 035501 (2002) 
66. Albert, J.N.L., Young, W.-S., Lewis, R.L., Bogart, T.D., Smith, J.R., Epps, T.: Systematic study on the effect of solvent removal rate on the morphology of solvent vapor annealed ABA triblock copolymer thin films. ACS Nano 6, 459 (2012)

67. Thurn-Albrecht, T., Schotter, J., Kastle, G.A., Emley, N., Shibauchi, T., Krusin-Elbaum, L., Guarini, K., Black, C.T., Tuominen, M.T., Russell, T.P.: Ultrahigh-density nanowire arrays grown in self-assembled diblock copolymer templates. Science 290, 2126 (2000)

68. Xu, T., Hawker, C.J., Russell, T.P.: Interfacial energy effects on the electric field alignment of symmetric diblock copolymers. Macromolecules 36, 6178 (2003)

69. DeRouchey, J., Thurn-Albrecht, T., Russell, T.P., Kolb, R.: Block copolymer domain reorientation in an electric field: an in-situ small-angle x-ray scattering study. Macromolecules 37, 2538 (2004)

70. Pereira, G.G., Williams, D.R.M.: Diblock copolymer melts in electric fields: the transition from parallel to perpendicular alignment using a capacitor analogy. Macromolecules 32, 8115 (1999)

71. Tsori, Y., Andelman, D.: Thin film diblock copolymers in electric field: transition from perpendicular to parallel lamellae. Macromolecules 35, 5161 (2002)

72. Tsori, Y., Tournilhac, F., Andelman, D., Leibler, L.: Structural changes in block copolymers: coupling of electric field and mobile ions. Phys. Rev. Lett. 90, 145504 (2003)

73. Thurn-Albrecht, T., DeRouchey, J., Russell, T.P., Kolb, R.: Pathways toward electric field induced alignment of block copolymers. Macromolecules 35, 8106 (2002)

74. Böker, A., Elbs, H., Hänsel, H., Knoll, A., Ludwigs, S., Zettl, H., Zvelindovsky, A.V., Sevink, G.J.A., Urban, V., Abetz, V., Müller, A.H.E., Krausch, G.: Electric field induced alignment of concentrated block copolymer solutions. Macromolecules 36, 8078 (2003)

75. Böker, A., Knoll, A., Elbs, H., Abetz, V., Müller, A.H.E., Krausch, G.: Large scale domain alignment of a block copolymer from solution using electric fields. Macromolecules 35, 1319 (2002)

76. Chen, Z.R., Kornfield, J.A., Smith, S.D., Grothaus, J.T., Satkowski, M.M.:Pathways to macroscale order in nanostructured block copolymers Science 277, 1248 (1997)

77. Polis, D.L., Smith, S.D., Terrill, N.J., Ryan, A.J., Morse, D.C., Winey, K.I.: Shear-induced lamellar rotation observed in a diblock copolymer by in situ small-angle $\mathrm{x}$-ray scattering. Macromolecules 32, 4668 (1999)

78. Chen, P.L.: Shear alignments in three-dimensional simulations of lamellar phases. Phys. Rev. E 71, 061503 (2005)

79. Fasolka, M.J., Mayes, A.M.: Block copolymer thin films: physics and applications. Annu. Rev. Mater. Res. 31, 323 (2001)

80. Angelescu, D.E., Waller, J.H., Register, R.A., Chaikin, P.M.: Shear-induced alignment in thin films of spherical nanodomains. Adv. Mater. 17, 1878 (2005)

81. Pujari, S., Keaton, M.A., Chaikin, P.M., Register, R.A.: Alignment of perpendicular lamellae in block copolymer thin films by shearing. Soft Matter 8, 5358 (2012)

82. Darling, S.B.: Directing the self-assembly of block copolymers. Prog. Polym. Sci. 32, 1152 (2007)

83. Hashimoto, T., Bodycomb, J., Funaki, Y., Kimishima, K.: The effect of temperature gradient on the microdomain orientation of diblock copolymers undergoing an order-disorder transition. Macromolecules 32, 952 (1999)

84. Mita, K., Tanaka, H., Saijo, K., Takenaka, M., Hashimoto, T.: Cylindrical domains of block copolymers developed via ordering under moving temperature gradient. Macromolecules 40, 5923 (2007)

85. Turner, M.S., Rubinstein, M., Marques, C.M.: Surface-induced lamellar ordering in a hexagonal phase of diblock copolymers. Macromolecules 27, 4986 (1994)

86. Green, P.F.: Wetting and dynamics of structured liquid films. J. Polym. Sci. B Polym. Phys. 41, 2219 (2003)

87. Maaloum, M., Chatenay, D., Coulon, G., Gallot, Y.: Edge profile of relief 2D domains at the free surface of smectic copolymer thin films. Phys. Rev. Lett. 68, 1575 (1992) 
88. Smith, A.P., Douglas, J.F., Meredith, J.C., Amis, E.J., Karim, A.: High-throughput characterization of pattern formation in symmetric diblock copolymer films. J. Polym. Sci. B Polym. Phys. 39, 2141 (2001)

89. Coulon, G., Collin, B., Chatenay, D., Gallot, Y.: Kinetics of growth of islands and holes on the free surface of thin diblock copolymer films. J. Phys. 3, 697 (1993). II France

90. Smith, A.P., Douglas, J.F., Meredith, J.C., Amis, E.J., Karim, A.: Combinatorial study of surface pattern formation in thin block copolymer films. Phys. Rev. Lett. 87, 015503 (2001)

91. Li, Z., Qu, S., Rafailovich, M.H., Sokolov, J., Tolan, M., Turner, M.S., Wang, J., Schwarz, S. A., Lorenz, H., Kotthaus, J.P.: Confinement of block copolymers on patterned surfaces. Macromolecules 30, 8410 (1997)

92. Xu, T., Goldbach, J.T., Russell, T.P.: Sequential, orthogonal fields: a path to long-range, 3-D order in block copolymer thin films. Macromolecules 36, 7296 (2003)

93. Ye, C.H., Singh, G., Wadley, M.L., Karim, A., Cavicchi, K.A., Vogt, B.D.: Anisotropic mechanical properties of aligned polystyrene-block-polydimethylsiloxane thin films. Macromolecules 46, 21 (2013)

94. Berry, B.C., Singh, G., Kim, H.-C., Karim, A.: Highly aligned block copolymer thin films by synergistic coupling of static graphoepitaxy and dynamic thermal annealing fields. ACS Macro Lett. 2, 346 (2013)

95. Hong, S.W., Huh, J., Gu, X.D., Lee, D.H., Jo, W.H., Park, S., Xu, T., Russell, T.P.: Unidirectionally aligned line patterns driven by entropic effects on faceted surfaces. Proc. Natl. Acad. Sci. U. S. A. 109, 1402 (2012)

96. Man, X., Andelman, D., Orland, H., Thébault, P., Liu, P.H., Guenoun, P., Daillant, J., Landis, S.: Organisation of block copolymers using nanoimprint lithography: comparison of theory and experiments. Macromolecules 44, 2206 (2011)

97. Park, S.-M., Liang, X., Harteneck, B.D., Pick, T.E., Hiroshiba, N., Wu, Y., Helms, B.A., Olynick, D.L.: Sub-10 nm nanofabrication via nanoimprint directed self-assembly of block copolymers. ACS Nano 5, 8523 (2011)

98. Tang, C., Wu, W., Smilgies, D.-M., Matyjaszewski, K., Kowalewski, T.: Robust control of microdomain orientation in thin films of block copolymers by zone casting. J. Am. Chem. Soc. 133, 11802 (2011)

99. Seppala, J.E., Lewis, R.L., Epps, T.H.: Spatial and orientation control of cylindrical nanostructures in ABA triblock copolymer thin films by raster solvent vapor annealing. ACS Nano 6, 9855 (2012)

100. Yager, K.G., Fredin, N.J., Zhang, X., Berry, B.C., Karim, A., Jones, R.L.: Evolution of blockcopolymer order through a moving thermal zone. Soft Matter 6, 92 (2010)

101. Stoykovich, M.P., Muller, M., Kim, S.O., Solak, H.H., Edwards, E.W., Pablo, J.J., Nealey, P.F.: Directed assembly of block copolymer blends into nonregular device-oriented structures. Science 308, 1442 (2005)

102. Hahm, J., Sibener, S.J.: Time-resolved atomic force microscopy imaging studies of asymmetric PS-b-PMMA ultrathin films: dislocation and disclination transformations, defect mobility, and evolution of nanoscale morphology. J. Chem. Phys. 114, 4730 (2001)

103. Anastasiadis, S.H., Russell, T.P., Satija, S.K., Majkrzak, C.F.: Neutron reflectivity studies of the surface-induced ordering of diblock copolymer films. Phys. Rev. Lett. 62, 1852 (1989)

104. Ree, M.: Probing the self- assembled nanostructures of functional polymers with synchrotron grazing incidence x-ray scattering. Macromol. Rapid Commun. 35, 930 (2014)

105. Renaud, G., Lazzari, R., Leroy, F.: Probing surface and interface morphology with grazing incidence small-angle Y-ray scattering. Surf. Sci. Rep. 64, 255 (2009)

106. Lu, X., Yager, K.G., Johnston, D., Black, C.T., Ocko, B.M.: Grazing-incidence transmission $\mathrm{X}$-ray scattering: surface scattering in the Born approximation. J. Appl. Crystal. 46, 165 (2013)

107. Azzam, R.M.A., Bashara, N.M.: Ellipsometry and Polarized Light. Elsevier, Amsterdam (1987) 
108. Johannsmann, D.: Investigation of soft organic films with ellipsometry. In: Knoll, W., Advincula, R.C. (eds.) Functional Polymer Films, Characterization and Applications, vol. 2. Wiley, Weinheim (2011)

109. Virgili, J.M., Tao, Y., Kortright, J.B., Balsara, N.P., Segalman, R.A.: Analysis of order formation in block copolymer thin films using resonant soft $\mathrm{X}$-ray scattering. Macromolecules 40, 2092 (2007)

110. Sunday, D.F., Hammond, M.R., Wang, C.Q., Wu, W.-L., Delongchamp, D.M., Tjio, M., Cheng, J.Y., Pitera, J.W., Kline, R.J.: Determination of the internal morphology of nanostructures patterned by directed self-assembly. ACS Nano 8, 8426 (2014)

111. Filimon, M., Kopf, I., Ballout, F., Schmidt, D.A., Bründermann, E., Rühe, J., Santer, S., Havenith, M.: Smart polymer surfaces: mapping chemical landscapes on the nanometre scale. Soft Matter 6, 3764 (2010)

112. Chang, J.B., Choi, H.K., Hannon, A.F., Alexander-Katz, A., Ross, C.A., Berggren, K.K.: Design rules for self-assembled block copolymer patterns using tiled templates. Nat Commun. 5, 3305 (2014)

113. Cushen, J.D., Otsuka, I., Bates, C.M., Halila, S., Fort, S., Rochas, C., Easley, J.A., Rausch, E.L., Thio, A., Borsali, R., Willson, C.G., Ellison, C.J.: Oligosaccharide/silicon-containing block copolymers with $5 \mathrm{~nm}$ features for lithographic applications. ACS Nano 6, 3424 (2012)

114. Kim, S.H., Misner, M.J., Yang, L., Gang, O., Ocko, B.M., Russell, T.P.: Salt complexation in block copolymer thin films. Macromolecules 39, 8473 (2006)

115. Kim, S., Nealey, P.F., Bates, F.S.: Directed assembly of lamellae forming block copolymer thin films near the order-disorder transition. Nano Lett. 14, 148 (2014)

116. Mishra, V., Fredrickson, G.H., Kramer, E.J.: Effect of film thickness and domain spacing on defect densities in directed self-assembly of cylindrical morphology block copolymers. ACS Nano 6, 2629 (2012)

117. Jong, S., Moon, H.C., Kwak, J., Bae, D., Lee, Y., Kim, J.K., Lee, W.B.: Phase behavior of star-shaped polystyrene-block-poly(methyl methacrylate) copolymers. Macromolecules 47, 5295 (2014)

118. Hexemer, A., Vitelli, V., Kramer, E.J., Fredrickson, G.H.: Monte Carlo study of crystalline order and defects on weakly curved surfaces. Phys. Rev. E 76, 051604 (2007)

119. Vitelli, V., Lucks, J.B., Nelson, D.R.: Crystallography on curved surfaces. Proc. Natl. Acad. Sci. U. S. A. 103, 12323 (2006)

120. Stuart, M.A.C., Huck, W.T.S., Genzer, J., Müller, M., Ober, C., Stamm, M., Sukhorukov, G.B., Szleifer, I., Tsukruk, V.V., Urban, M., Winnik, F., Zauscher, S.I., Luzinov, I., Minko, S.: Emerging applications of stimuli-responsive polymer materials. Nat. Mater. 9, 101 (2010)

121. Kelly, J.Y., Albert, J.N.L., Howarter, J.A., Kang, S., Stafford, C.M., Epps, T.H., Fasolka, M. J.: Investigation of thermally responsive block copolymer thin film morphologies using gradients. ACS Appl. Mater. Interfaces 2, 3241 (2010) 